\title{
Erratum to: Metabolic profile of salidroside in rats using high-performance liquid chromatography combined with Fourier transform ion cyclotron resonance mass spectrometry
}

Fei Han ${ }^{1} \cdot$ Yan-ting $\mathrm{Li}^{1} \cdot$ Xin-juan $\mathrm{Mao}^{1} \cdot$ Xiao-shu $\mathrm{Zhang}^{1} \cdot$

Jiao Guan ${ }^{1} \cdot$ Ai-hua Song ${ }^{1} \cdot$ Ran Yin $^{1}$

Received: 11 December 2015 / Accepted: 11 December 2015 / Published online: 18 January 2016

(C) Springer-Verlag Berlin Heidelberg 2016

Erratum to: Anal Bioanal Chem

DOI 10.1007/s00216-015-9080-9

The name of corresponding author Ran Yin was inadvertently inverted in both the pdf and $\mathrm{xml}$ versions of this article. The authors regret their error.

The correct form is presented here and the original article was corrected.

The online version of the original article can be found at http://dx.doi.org/ 10.1007/s00216-015-9080-9.

\footnotetext{
Ai-hua Song

songaihua62630@163.com

yinran_syspu@163.com
}

$\triangle$ Ran Yin

School of Pharmacy, Shenyang Pharmaceutical University, 103

Wenhua Road, Shenhe District, Shenyang 110016, China 